\title{
Intraperitoneal Injection of Multiplacentas Pooled Cells Treatment on a Mouse Model with Aplastic Anemia
}

\author{
Jun Li, ${ }^{1,2}$ Hong Chen, ${ }^{3}$ Yan-Bo Lv, ${ }^{2}$ Qiang Wang, ${ }^{2}$ Zheng-Jun Xie, ${ }^{4}$ Li-Hua Ma, ${ }^{2}$ Jie He, \\ Wei Xue, ${ }^{1}$ Shan Yu, ${ }^{1}$ Jun Guo, ${ }^{5}$ Ting-Hua Wang, ${ }^{6}$ Tian-Xi Wu, ${ }^{1}$ and Xing-Hua Pan ${ }^{2}$ \\ ${ }^{1}$ Medical School, Kunming University, Kunming 650214, China \\ ${ }^{2}$ Stem Cell, Tissue and Organ Engineering Research Center, Kunming General Hospital of Chengdu Military Command, \\ Kunming 650032, China \\ ${ }^{3}$ Department of Oncology, Kunming General Hospital of Chengdu Military Command, Kunming 650032, China \\ ${ }^{4}$ Department of Haematology and Endocrinology, Kunming General Hospital of Chengdu Military Command, \\ Kunming 650032, China \\ ${ }^{5}$ Digestive System Department, Kunming General Hospital of Chengdu Military Command, Kunming 650032, China \\ ${ }^{6}$ Neuroscience Institute of Kunming Medical University, Kunming 650500, China
}

Correspondence should be addressed to Xing-Hua Pan; 247467246@qq.com

Received 31 August 2015; Revised 28 December 2015; Accepted 10 January 2016

Academic Editor: Jenny Persson

Copyright (C) 2016 Jun Li et al. This is an open access article distributed under the Creative Commons Attribution License, which permits unrestricted use, distribution, and reproduction in any medium, provided the original work is properly cited.

\begin{abstract}
Coinfusion of hematopoietic and mesenchymal stem cells is more effective than hematopoietic stem cell transplantation alone. It is necessary to explore a safe and routine mixed stem cell intraperitoneal transplantation method. Multiplacentas pooled cells were intraperitoneally injected into a radiation- and immunity-induced mouse aplastic anemia model with single time. Then, mouse survival time, peripheral blood hemoglobin count, bone marrow architecture, and donor cell engraftment were assessed. The recipient mouse exhibited donor cell engraftment in both bone marrow and peripheral blood. Survival time and peripheral blood hemoglobin count increased in placenta pooled cells treated mice, compared with model-only controls $(P=0.048$ and $P=0.000$, resp.). However, placentas pooled cells failed to cause a significant decrease in bone marrow pimelosis area $(P=0.357)$. Intraperitoneally transplanted multiplacentas pooled cells can survive and engraft into a host body through blood circulation, which can increase the life span of an aplastic anemia model mice, and delay but not abrogate the development of aplastic anemia. Furthermore, they appear to play a role in increasing peripheral blood hemoglobin level response for increasing the life span of aplastic anemia model mice.
\end{abstract}

\section{Introduction}

Aplastic anemia is a refractory disease that has a high fatality rate, and the destruction of hematopoietic cells by the immune system leads to pancytopenia [1]. Stem cells exhibit promising treatment effectiveness [2]. However, it is currently not a routine clinical treatment. One possible reason is the different impacts of the sources of cells with different properties of cells in a given heterogeneous population on the same condition [3]. It is necessary to explore a new stem cell therapeutic measure.
Current cell therapy protocols utilize umbilical cord tissue derived mesenchymal stem cells as an alternative to bone marrow mesenchymal stem cells [4]. The placenta is often a clinical waste product. It contains plenty of more primitive and immature stem cells than the adult bone marrow and contains hematopoietic stem cells, umbilical cord derived mesenchymal stem cells, umbilical cord blood mesenchymal stem cells, placenta derived mesenchymal stem cells, and so on [5-16]. Thus, allogenic transplantation research has made use of these stem cells for their pluripotency and immunological properties [17-19]. 
It has been reported that the cotransplantation of mesenchymal and hematopoietic stem cells is safe and more effective than hematopoietic stem cell transplantation alone [20]. Kadekar et al. reported that placenta derived mesenchymal stem cells are the most suitable feeders for the ex vivo maintenance of functional hematopoietic stem cells [4]. In addition, we found that the coculture of multiunit umbilical cord blood mesenchymal stem cells can dramatically boost their proliferation (unpublished), which is in accordance with the idea that double-unit cord blood grafts improve engraftment and reduce relapse risk [21, 22]. Furthermore, several studies have shown that intraperitoneally transplanted stem cells could engraft into host multiorgans $[23,24]$. Taken together, we explored the impact of intraperitoneal injection of multiplacentas deprived mixed cells treatment on a mouse model with aplastic anemia.

\section{Materials and Methods}

2.1. Mice. In order to induce an aplastic anemia model, twomonth-old inbred female BALB/cBy (H2d) and DBA/2 (H2d) mice were obtained from Kunming Medical University and Google Organisms, respectively, and were bred and maintained in the SPF animal facility of Kunming General Hospital of Chengdu Military Command under standard care and nutrition. The local institutional review board of Kunming General Hospital of Chengdu Military Command, under the auspices of the National Ministry of Heath, approved all of experimental procedures used in this study. One hundred fifty recipient $\mathrm{BALB} / \mathrm{cBy}$ mice were equally divided into two parts: Part 1 and Part 2, with a complete randomized design. Then, each part was equally divided into the model-only control (vehicle), the healthy normal control, and multiplacentas pooled cells treatment group. Each group contained 25 mice. Posttransplantation survival time was only observed in mice in Part 1, while other detections such as peripheral blood hemoglobin count, bone marrow architecture, and donor cell engraftment were performed in mice in Part 2.

2.2. Induction of Aplastic Anemia. BALB/cBy mice received a sublethal total body irradiation dose of 4 Gy from Model 143 ${ }^{137}$ Cesium $\gamma$-irradiator (JL Shepherd) one hour before lymph node cell infusion. Inguinal, brachial, and axillary infusion of lymph node cells were obtained from female DBA/2 mice, as previously described [25-27]; and they were infused into female $\mathrm{BALB} / \mathrm{cBy}$ mice at $1 \times 10^{6}$ cells per recipient to induce aplastic anemia.

2.3. Isolation of Placentas Cells. Allogene mice multiplacentas (containing placenta, umbilical cord, and umbilical cord blood) derived mixed cells were obtained from green fluorescent protein-expressing transgenic inbred parturient C57BL/6J mice ( $\mathrm{H} 2 \mathrm{~b}$, provided by the Neuroscience Institute of Kunming Medical University). Irregardless of gender, C57BL/6J F1 mice placentas were mixed together, grinded, and filtered through a 100-eye cell sieve mesh to obtain a single-cell suspension. Then, cells were centrifuged at $750 \mathrm{~g}$ for 20 minutes with gradient Percoll (GE Healthcare AB, Uppsala, Sweden; http://www.amersham.com/) to obtain a $1.070-1.090 \mathrm{~g} / \mathrm{cm}^{3}$ cell density (rich in stem cell). Cells were washed twice in Nutrient Mixture F-12 (Gibco ${ }^{\circledR}$ DMEM/F12) Media and counted using a Vi-Cell counter (Coulter Cooperation) [28]. Then, cells were ready for use.

2.4. Multiplacentas Pooled Cell Treatment. For multiplacentas pooled cells treatment, when bone marrow failure was already apparent at seven days after total body irradiation, $1 \mathrm{~mL}$ of mixed cell suspension in Nutrient Mixture F-12 Media was intraperitoneally injected into $\mathrm{BALB} / \mathrm{cBy}$ mice in the multiplacentas pooled cells transplanted group at $1 \times 10^{7}$ cells per mouse with single time. The model-only control mice received the same volume of vehicle, while healthy normal controls did not receive any treatment.

2.5. Survival Time, Peripheral Blood Hemoglobin Count, Bone Marrow Architecture, and Donor Cell Engraftment Detection. After transplantation, posttransplantation survival time of mice in Part 1 was examined and compared. When any mouse in Part 1 or Part 2 was almost dying, mice in Part 2 were initially bled for peripheral blood donor cell engraftment determination and hemoglobin count using an F-820 vet hematology analyzer (Sysmex, Japan). Then, mice were sacrificed to collect femurs for bone marrow donor cell engraftment and histologic examination.

Aplastic anemia concerned morphological changes of bone marrow architecture, which were observed by bone marrow histologic examination. The mouse left femur was fixed in $10 \%$ neutral buffered formalin, decalcified, embodied and sectioned into slides, and stained with hematoxylin and eosin. Slides were viewed using an Olympus microscope, and bone marrow morphology photographic images were captured at 400x magnification. The bone marrow pimelosis area per visual field was counted with a reticulum micrometer using the counting dots method of quantitative pathology.

Fluorescent protein tracing donor C57BL/6J mice cells engraftment and location were identified. The bone marrow was pushed out of the right femur of the mouse with the Nutrient Mixture F-12 Media and fully misced bene for antigrading. Each sample was smeared on the slide and subjected to fluorescence microscopy within a few hours. The image was acquired from the sample at 400x magnification and the number of green fluorescent protein positive cells per visual field was determined, as well as the peripheral blood smear.

2.6. Statistical Analysis. Summary statistics such as means and standard deviation were used to describe the mice samples' baseline characteristics. Group differences were examined by one-way ANOVA. For experiments that ANOVA justified, post hoc comparisons between group means were conducted using the LSD, S-N-K, and the Dunnett test for multiple comparisons. In the event in which only single experimental and control groups were used, group variance was examined by independent-samples $t$-test or the Wilcoxon Rank Sum Test. Differences were considered significant at $P<0.05$. All analyses were performed using the IBM SPSS 18.0 software. 


\section{Results}

All animals in Part 2 were bled and scarified when some mice were almost dying at day seven after transplantation for various analyses, as specified in each experiment.

3.1. Peripheral Blood Hemoglobin. Peripheral blood hemoglobin count was performed automatically in a hematology analyzer. Hemoglobin count was notably higher in the placentas pooled cells treated groups than in the model-only control group $(0.2948 \pm 0.04629$ versus $0.1460 \pm 0.03808$, $P=0.000)$. The number was as high as $1.3180 \pm 0.03202$ in healthy normal controls, which was significantly higher than model-only controls $(P=0.000$, Figure 1$)$.

3.2. Posttransplantation Survival Time. Mice in the healthy normal control group of Part 1 all survived until one month after transplantation. However, mortality to a $100 \%$ level was induced with aplastic anemia (other groups of Part 1) within 18 days. Thus, all mice in Part 1 were sacrificed at one month after treatment. Posttransplantation survival time in the healthy normal control group was significantly higher $(P=0.000)$ than in model-only controls. The survival time of the placentas pooled cells treated group $(13.320 \pm 2.704)$ was longer $(P=0.048)$ than in the model-only control group $(11.800 \pm 2.582$, Figure 2$)$.

3.3. Bone Marrow Histopathology. Typical bone marrow histopathology was observed in both the normal and experimental groups. Hematoxylin and eosin staining of the bone marrow exhibited that multiplacentas pooled cells treatment in mice marrow, which is the same as model-only controls, were filled with adipocytes with large empty spaces, compared with healthy normal controls that exhibited a densely packed cellular distribution in normal condition (Figure 3).

3.4. Bone Marrow Pimelosis Area. The bone marrow pimelosis areas in multiplacentas pooled cells treated mice, modelonly controls, and healthy normal controls were $55.866 \pm$ $6.0403 \%, 57.121 \pm 3.8636 \%$, and $11.031 \pm 1.8310 \%$, respectively. As shown in Figure 4, at day seven, the pimelosis area of healthy normal controls was significantly lower $(P=0.000)$ compared with model-only controls. At the same time, multiplacentas pooled cells treated mice had a lower pimelosis area than model-only controls, but the difference was not statistically significant $(P=0.357)$, as both groups had bone marrow hypocellularity.

3.5. Identification of Donor Cell. Twenty-five smear images were acquired for each group of mice in Part 2, and placentas pooled green fluorescent cells were observed. Every sample of mouse that received $10^{7}$ placentas pooled cells exhibited positive donor cell engraftment in both bone marrow and peripheral blood at day seven after transplantation (Figure 5), while other groups of mice in Part 2 did not reveal any positive cell (figure not shown).

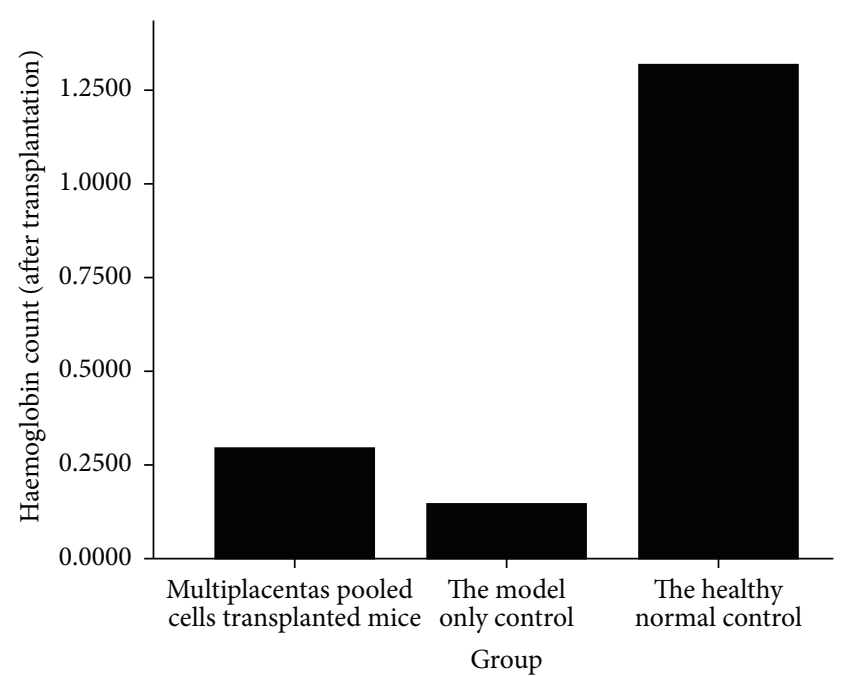

FIGURE 1: Mice peripheral blood hemoglobin count at day seven after placentas pooled cell treatment.

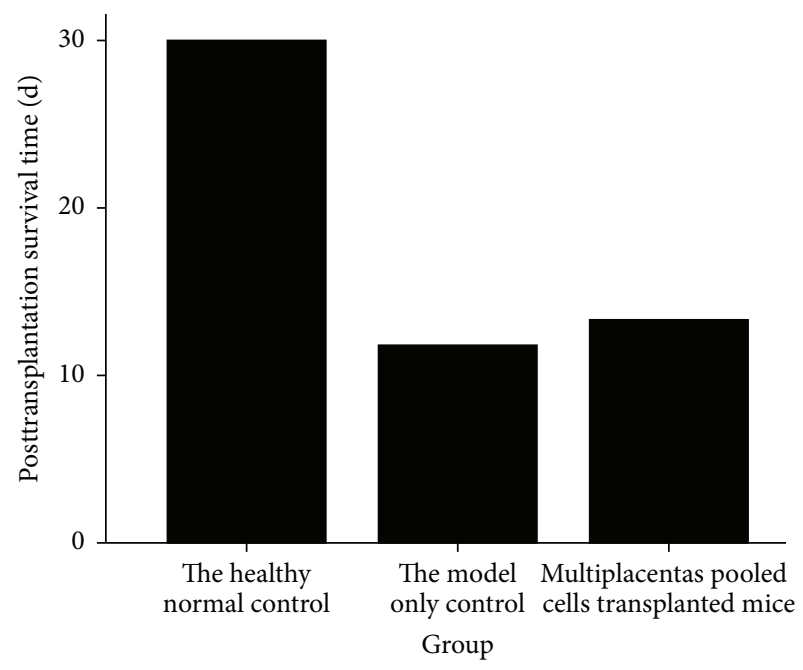

Figure 2: Posttransplantation survival time of mice in Part 1.

\section{Discussion}

Our study assessed the therapeutic effect and cellular mechanism of placentas pooled cells on aplastic anemia and a safe, effective stem cell therapeutic measure. Placental mesenchymal stromal cells are very primitive and have multipotent differentiation potency. The expansion potency of placenta derived mesenchymal stromal cells is higher compared to the bone marrow [17, 29]. Placenta derived mesenchymal and hematopoietic stem cells are homologous [4]. All these may contribute to treatment effectiveness.

We administrated the latest extracted primary cells with single time in order to avoid immunologic facilitation induced by repeated administration. Peripheral blood hemoglobin count, survival time, and the bone marrow pimelosis area were compared between the model-only control group and healthy normal controls. All differences were statistically significant (all $P=0.000$ ). The dates revealed 


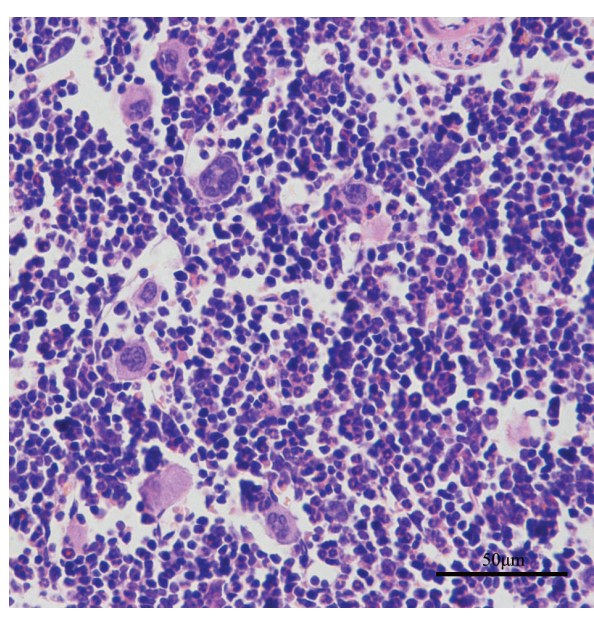

(a)

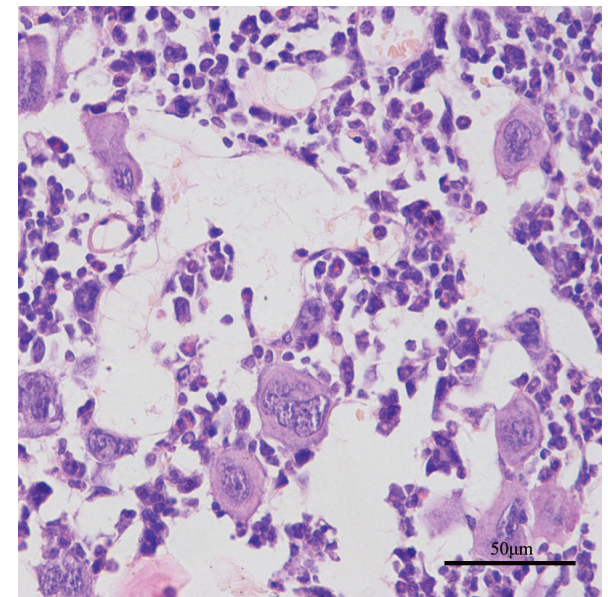

(b)

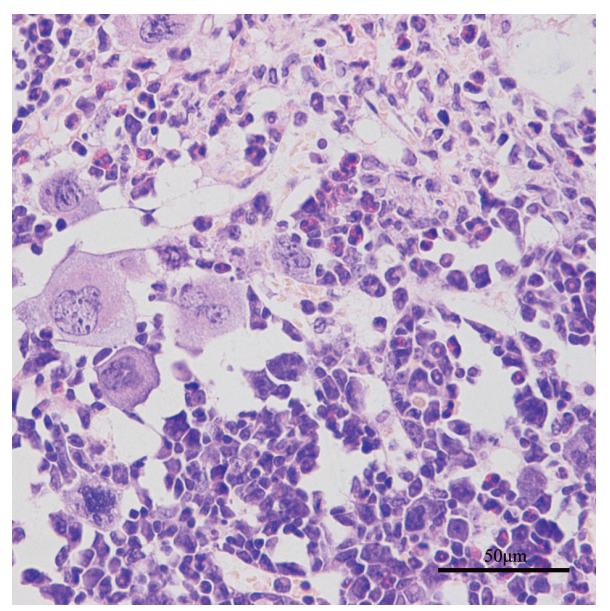

(c)

FiguRE 3: Mice bone marrow histopathology at day seven after placentas pooled cells treatment (400x). (a) Healthy normal controls; (b) model-only controls; (c) multiplacentas pooled cells transplanted mice.

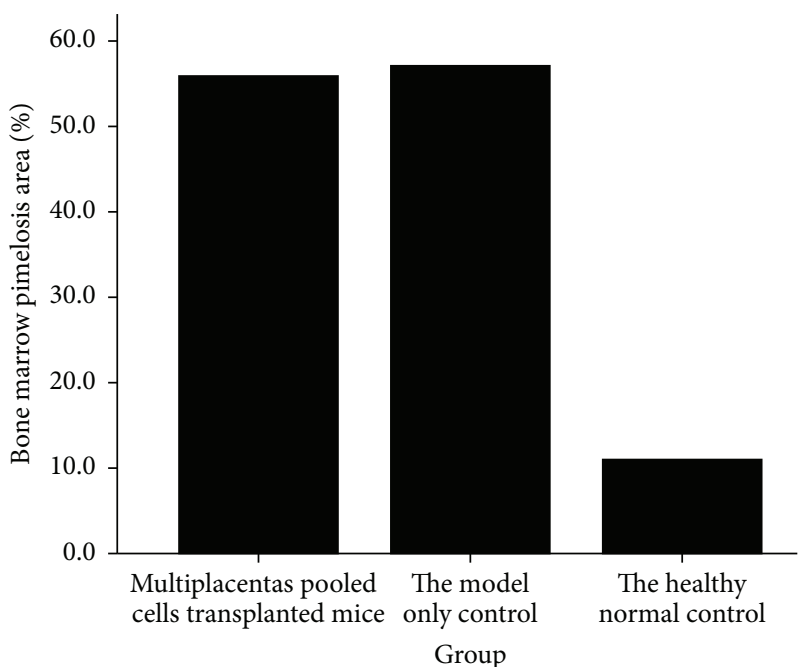

FIGURE 4: Mice bone marrow pimelosis area at day seven after placentas pooled cells treatment. that the radiation and immunity mediated model induced long-term aplastic anemia. Posttransplantation survival time dates indicate that the intraperitoneal transplantation of multiplacentas pooled cells can increase the life span of aplastic anemia model mice, and transplants are capable of delaying but not abrogating the development of aplastic anemia.

Treatment effectiveness depends on the number of transplanted cells. Currently, the number of patients transplanted with double umbilical cord blood has surpassed the number of receiving single cord blood unit [30]. Thus, we administrated $1 \times 10^{7}$ multiplacentas pooled mixed cells per mouse with intraperitoneal injection transplantation. Mesenchymal stem cells can adhere to the peritoneum, which can support and carry it into the blood circulation [31]. In addition, we found the presence of donor cells in both the recipient's bone marrow and peripheral blood. It indicates that intraperitoneally injected placentas derived cells survive and engraft into the host body through blood circulation. 


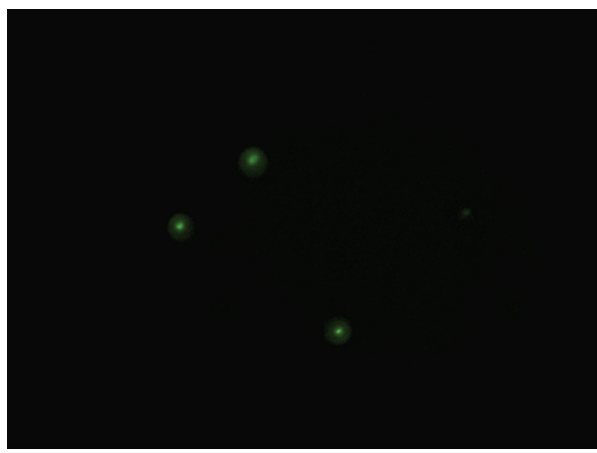

Bone marrow smear

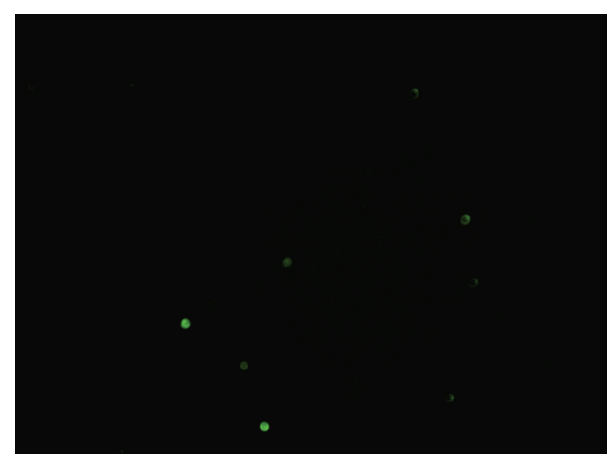

Blood smear

FIGURE 5: The multiplacentas pooled cells transplanted mice exhibited positive donor cell engraftment at day seven after transplantation (400x).

Multiplacentas pooled cells treatment mice had a lower pimelosis area than model-only controls, but the difference was not statistically significant. However, donor cells significantly increased in peripheral blood hemoglobin levels. Thus, placentas pooled cells appear to play a role in increasing peripheral blood hemoglobin level response for increasing the life span of aplastic anemia model mice. Pimelosis area decreased much lower than the level of increase in peripheral blood hemoglobin, which might explain why placentas pooled cells can only delay the development of aplastic anemia.

Treated cells contained plenty of hematopoietic stem cells, mesenchymal stem cells, hematopoietic progenitor cells, hemopoiesis precursor cells, erythrocytes, and leucocytes [5-16]. These cells can initially migrate into blood vessels and into the bone marrow of aplastic anemia. In particular, hematopoietic stem cells can differentiate into erythrocytes, leucocyte, and so on. In addition, mesenchymal stem cells can promote hemopoiesis and modulate immunoreaction induced by DBA/2 mouse lymphocytes injected into the host blood vascular system [32-35]. All these may contribute to its promising treatment effectiveness. However, although these stem cells may prolong survival time, they could not effectively improve the bone marrow pathology architecture of mice.

\section{Conclusion}

Results indicate that the intraperitoneal transplantation of multiplacentas pooled cells can increase the life span of aplastic anemia model mice and delay but not abrogate the development of aplastic anemia. Intraperitoneally transplanted cells can survive and engraft into the host body through blood circulation. Improvement of peripheral blood hemoglobin levels, but not bone marrow architecture response, probably explains the increase in survival time observed in this study.

\section{Disclaimer}

The authors are solely responsible for the contents and writing of this paper.

\section{Conflict of Interests}

The authors declare no competing interests.

\section{Acknowledgments}

This work was supported by grants from the National Natural Science Fund (311721702011), the Yunnan Provincial Science and Technology Department Applied Basic Research Project (2011FZ322, 2013FZ097), the Kunming University Science Research Project (XJL12029), and the 2012 Year Undergraduate Student Innovation \& Carve Out Training Program Granting Project of Yunnan Province. The authors thank the staff of the Neuroscience Institute of Kunming Medical University for their valuable technical assistance.

\section{References}

[1] T. Yoshizato, B. Dumitriu, K. Hosokawa et al., "Somatic mutations and clonal hematopoiesis in aplastic anemia," The New England Journal of Medicine, vol. 373, no. 1, pp. 35-47, 2015.

[2] K. Kudo, H. Muramatsu, N. Yoshida et al., "Second allogeneic hematopoietic stem cell transplantation in children with severe aplastic anemia," Bone Marrow Transplantation, vol. 50, no. 10, pp. 1312-1315, 2015.

[3] Y. Z. Zhu, Y. X. Yang, Y. L. Zhang et al., "Placental mesenchymal stem cells of fetal and maternal origins demonstrate different therapeutic potentials," Stem Cell Research \& Therapy, vol. 5, article 48, 2014.

[4] D. Kadekar, V. Kale, and L. Limaye, "Differential ability of MSCs isolated from placenta and cord as feeders for supporting ex vivo expansion of umbilical cord blood derived CD $34^{+}$cells," Stem Cell Research \& Therapy, vol. 6, article 201, 2015.

[5] M. Mimeault and S. K. Batra, "Concise review: recent advances on the significance of stem cells in tissue regeneration and cancer therapies," Stem Cells, vol. 24, no. 11, pp. 2319-2345, 2006.

[6] R. Mahmood, M. S. Choudhery, A. Mehmood, S. N. Khan, and S. Riazuddin, "In vitro differentiation potential of human placenta derived cells into skin cells," Stem Cells International, vol. 2015, Article ID 841062, 11 pages, 2015. 
[7] G. G. Wulf, V. Viereck, B. Hemmerlein et al., "Mesengenic progenitor cells derived from human placenta," Tissue Engineering, vol. 10, no. 7-8, pp. 1136-1147, 2004.

[8] S. Wolbank, M. van Griensven, R. Grillari-Voglauer, and A. Peterbauer-Scherb, "Alternative sources of adult stem cells: human amniotic membrane," in Bioreactor Systems for Tissue Engineering II, vol. 123 of Advances in Biochemical Engineering/Biotechnology, pp. 1-27, Springer, Berlin, Germany, 2010.

[9] D. Rus Ciucă, O. Soriţău, S. Şuşman, V. I. Pop, and C. M. Mihu, "Isolation and characterization of chorionic mesenchyal stem cells from the placenta," Romanian Journal of Morphology and Embryology, vol. 52, no. 3, pp. 803-808, 2011.

[10] H. Karlsson, T. Erkers, S. Nava, S. Ruhm, M. Westgren, and O. Ringdén, "Stromal cells from term fetal membrane are highly suppressive in allogeneic settings in vitro," Clinical and Experimental Immunology, vol. 167, no. 3, pp. 543-555, 2012.

[11] H. K. A. Mikkola, C. Gekas, S. H. Orkin, and F. Dieterlen-Lievre, "Placenta as a site for hematopoietic stem cell development," Experimental Hematology, vol. 33, no. 9, pp. 1048-1054, 2005.

[12] C. Gekas, F. Dieterlen-Lièvre, S. H. Orkin, and H. K. A. Mikkola, "The placenta is a niche for hematopoietic stem cells," Developmental Cell, vol. 8, no. 3, pp. 365-375, 2005.

[13] K. Ottersbach and E. Dzierzak, "The murine placenta contains hematopoietic stem cells within the vascular labyrinth region," Developmental Cell, vol. 8, no. 3, pp. 377-387, 2005.

[14] K. E. Rhodes, C. Gekas, Y. Wang et al., "The emergence of hematopoietic stem cells is initiated in the placental vasculature in the absence of circulation," Cell Stem Cell, vol. 2, no. 3, pp. 252-263, 2008.

[15] I. M. Samokhvalov, "Deconvoluting the ontogeny of hematopoietic stem cells," Cellular and Molecular Life Sciences, vol. 71, no. 6, pp. 957-978, 2014.

[16] M. W. Lensch, L. Daheron, and T. M. Schlaeger, "Pluripotent stem cells and their niches," Stem Cell Reviews and Reports, vol. 2, no. 3, pp. 185-201, 2006.

[17] Z. Miao, J. Jin, L. Chen et al., "Isolation of mesenchymal stem cells from human placenta: comparison with human bone marrow mesenchymal stem cells," Cell Biology International, vol. 30, no. 9, pp. 681-687, 2006.

[18] R. Apps, S. P. Murphy, R. Fernando, L. Gardner, T. Ahad, and A. Moffett, "Human leucocyte antigen (HLA) expression of primary trophoblast cells and placental cell lines, determined using single antigen beads to characterize allotype specificities of antiHLA antibodies," Immunology, vol. 127, no. 1, pp. 26-39, 2009.

[19] O. Parolini and M. Caruso, "Review: preclinical studies on placenta-derived cells and amniotic membrane: an update," Placenta, vol. 32, supplement 2, pp. S186-S195, 2011.

[20] A. V. Vanikar, H. L. Trivedi, A. Feroze, K. V. Kanodia, S. D. Dave, and P. R. Shah, "Effect of co-transplantation of mesenchymal stem cells and hematopoietic stem cells as compared to hematopoietic stem cell transplantation alone in renal transplantation to achieve donor hypo-responsiveness," International Urology and Nephrology, vol. 43, no. 1, pp. 225-232, 2011.

[21] P. B. Dahi, J. Barone, S. M. Devlin et al., "Sustained donor engraftment in recipients of double-unit cord blood transplantation is possible despite donor-specific human leukoctye antigen antibodies," Biology of Blood and Marrow Transplantation, vol. 20, no. 5, pp. 735-739, 2014.

[22] J. A. Gutman, S. R. Riddell, S. McGoldrick, and C. Delaney, "Double unit cord blood transplantation: who wins-and why do we care?” Chimerism, vol. 1, no. 1, pp. 21-22, 2010.
[23] M. Ghionzoli, M. Cananzi, A. Zani et al., "Amniotic fluid stem cell migration after intraperitoneal injection in pup rats: implication for therapy," Pediatric Surgery International, vol. 26, no. 1, pp. 79-84, 2010.

[24] A. C. Piscaglia, C. Di Campli, M. A. Zocco et al., "Human cordonal stem cell intraperitoneal injection can represent a rescue therapy after an acute hepatic damage in immunocompetent rats," Transplantation Proceedings, vol. 37, no. 6, pp. 2711-2714, 2005.

[25] R. P. de Latour, V. Visconte, T. Takaku et al., "Thl7 immune responses contribute to the pathophysiology of aplastic anemia," Blood, vol. 116, no. 20, pp. 4175-4184, 2010.

[26] J. Chen, F. M. Ellison, M. A. Eckhaus et al., "Minor antigen H60-mediated aplastic anemia is ameliorated by immunosuppression and the infusion of regulatory $\mathrm{T}$ cells," Journal of Immunology, vol. 178, no. 7, pp. 4159-4168, 2007.

[27] M. L. Bloom, A. G. Wolk, K. L. Simon-Stoos, J. S. Bard, J. Chen, and N. S. Young, "A mouse model of lymphocyte infusioninduced bone marrow failure," Experimental Hematology, vol. 32, no. 12, pp. 1163-1172, 2004.

[28] J. Li, L. Zhang, L. Zhou et al., "Beneficial effects of non-matched allogeneic cord blood mononuclear cells upon patients with idiopathic osteoporosis," Journal of Translational Medicine, vol. 10, article 102, 2012.

[29] P. S. In’t Anker, S. A. Scherjon, C. Kleijburg-Van Der Keur et al., "Isolation of mesenchymal stem cells of fetal or maternal origin from human placenta," STEM CELLS, vol. 22, no. 7, pp. 13381345, 2004.

[30] A. Sideri, N. Neokleous, P. B. D. L. G. Grange et al., "An overview of the progress on double umbilical cord blood transplantation," Haematologica, vol. 96, no. 8, pp. 1213-1220, 2011.

[31] B. R. Blazar, P. A. Taylor, and D. A. Vallera, "In utero transfer of adult bone marrow cells into recipients with severe combined immunodeficiency disorder yields lymphoid progeny with Tand B-cell functional capabilities," Blood, vol. 86, no. 11, pp. 4353-4366, 1995.

[32] S. E. Haynesworth, M. A. Baber, and A. I. Caplan, "Cytokine expression by human marrow derived mesenchymal progenitor cells in vitro: effects of dexamethasone and IL-1 alpha," Journal of Cellular Physiology, vol. 166, no. 3, pp. 585-592, 1996.

[33] M. K. Majumdar, M. A. Thiede, J. D. Mosca, M. Moorman, and S. L. Gerson, "Phenotypic and functional comparison of cultures of marrow-derived mesenchymal stem cells (MSCs) and stromal cells," Journal of Cellular Physiology, vol. 176, no. 1, pp. 57-66, 1998.

[34] A. Bartholomew, C. Sturgeon, M. Siatskas et al., "Mesenchymal stem cells suppress lymphocyte proliferation in vitro and prolong skin graft survival in vivo," Experimental Hematology, vol. 30, no. 1, pp. 42-48, 2002.

[35] M. Di Nicola, C. Carlo-Stella, M. Magni et al., "Human bone marrow stromal cells suppress T-lymphocyte proliferation induced by cellular or nonspecific mitogenic stimuli," Blood, vol. 99, no. 10, pp. 3838-3843, 2002. 

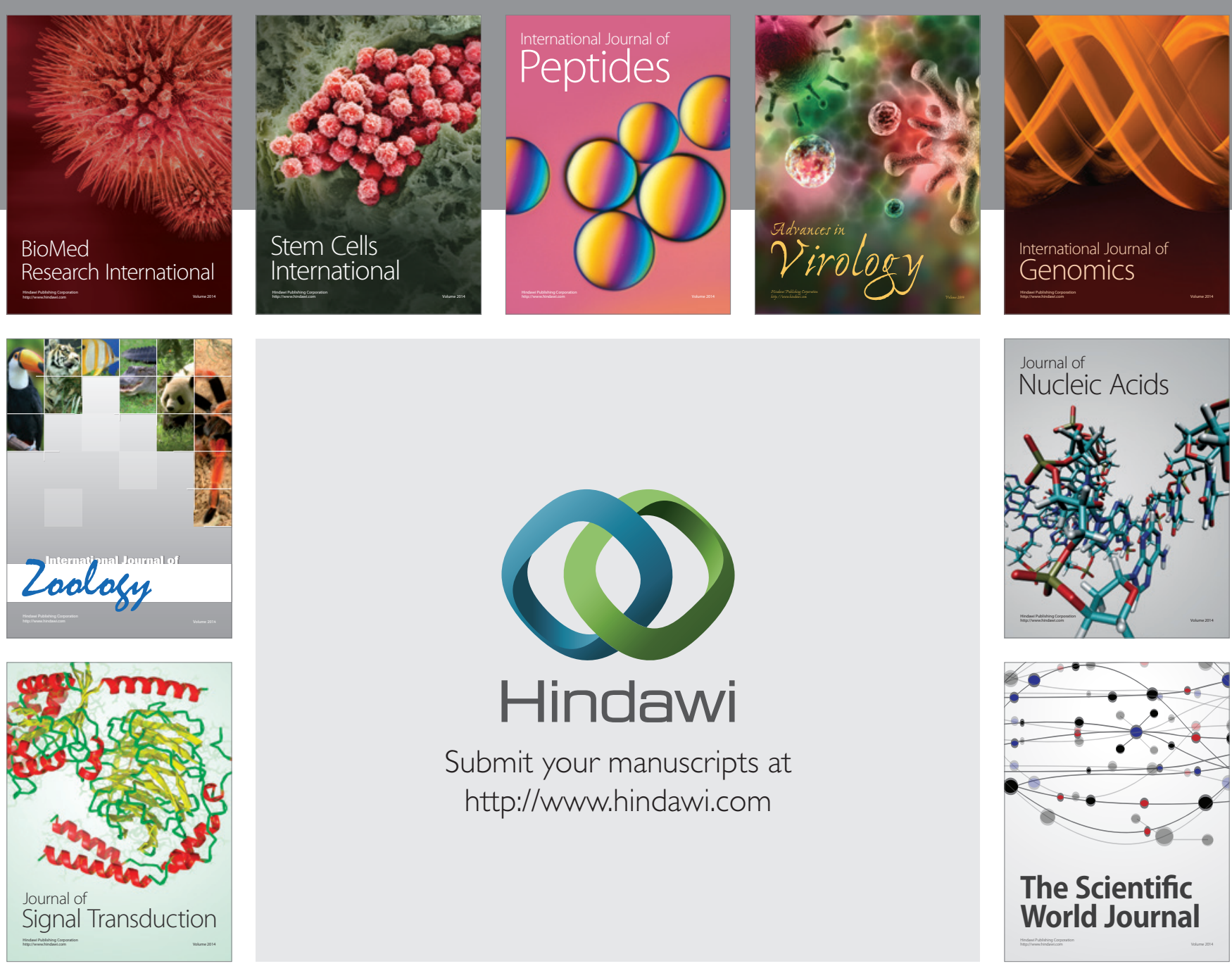

Submit your manuscripts at

http://www.hindawi.com
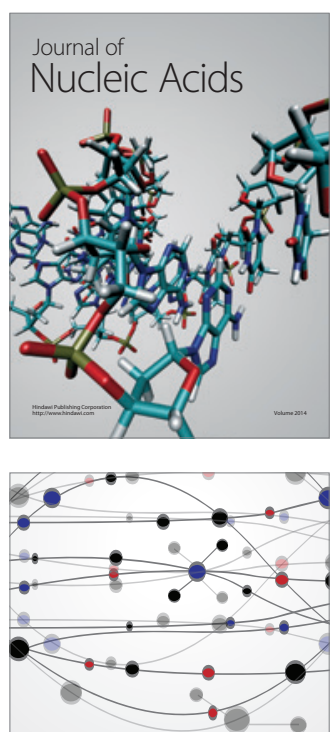

The Scientific World Journal
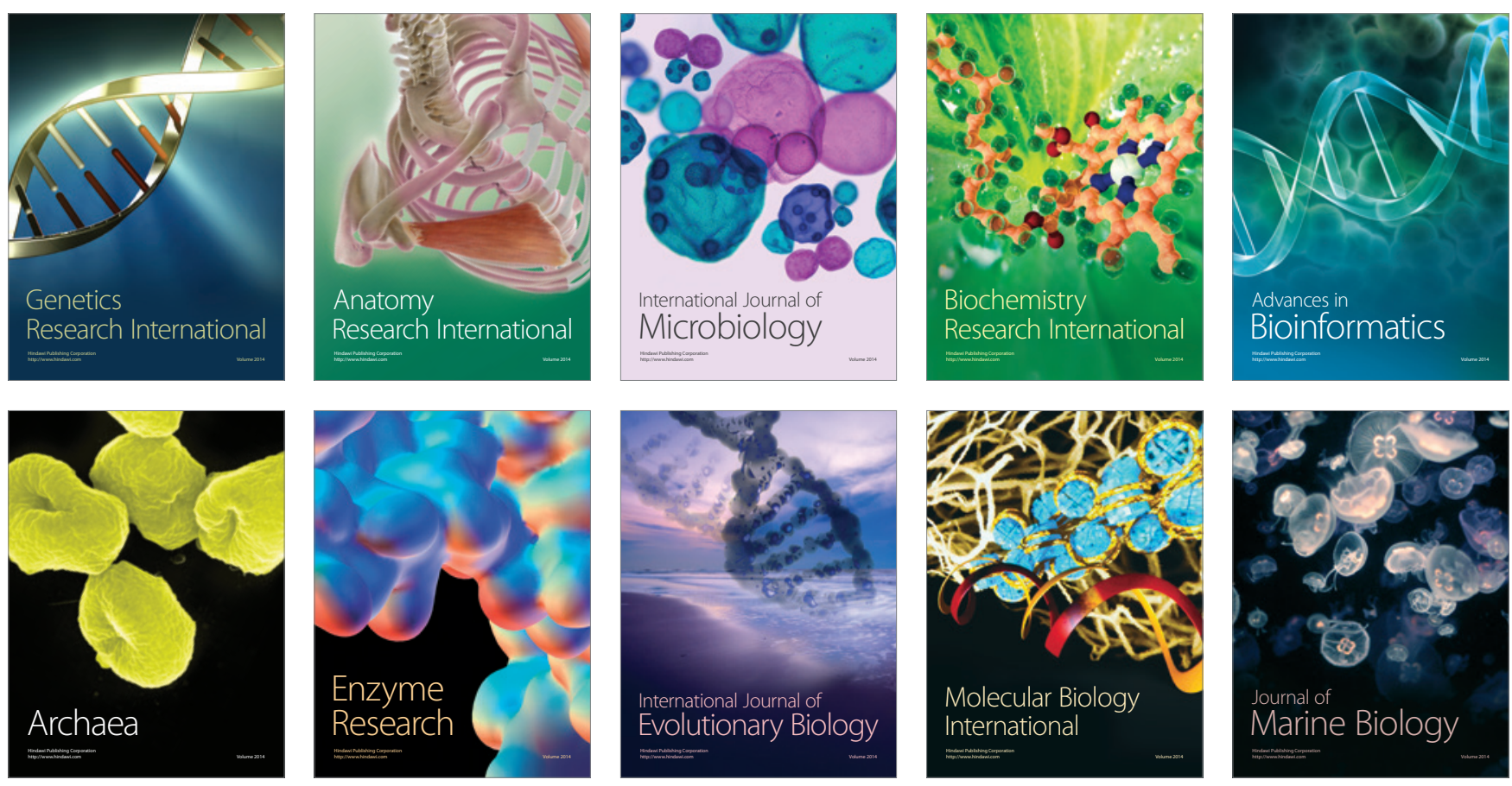